\title{
Moderating claims and disputes through collaborative procurement
}

Article

Accepted Version

Elhag, T., Eapen, S. and Ballal, T. (2020) Moderating claims and disputes through collaborative procurement. Construction Innovation: Information, Process, Management, 167. pp. 220231. ISSN 1471-4175 doi: https://doi.org/10.1108/CI-02-20190020 Available at https://centaur.reading.ac.uk/86921/

It is advisable to refer to the publisher's version if you intend to cite from the work. See Guidance on citing.

To link to this article DOI: http://dx.doi.org/10.1108/CI-02-2019-0020

Publisher: Emerald

All outputs in CentAUR are protected by Intellectual Property Rights law, including copyright law. Copyright and IPR is retained by the creators or other copyright holders. Terms and conditions for use of this material are defined in the End User Agreement.

\section{www.reading.ac.uk/centaur}

\section{CentAUR}

Central Archive at the University of Reading

Reading's research outputs online 


\section{Moderating Claims and Disputes through Collaborative Procurement}

\begin{tabular}{|r|l|}
\hline Journal: & Construction Innovation: Information, Process, Management \\
\hline Manuscript ID & CI-02-2019-0020 \\
\hline Manuscript Type: & Research Article \\
\hline Keywords: & $\begin{array}{l}\text { UAE construction industry, collaborative procurement, traditional } \\
\text { systems, claims, disputes, cultural change }\end{array}$ \\
\hline \multicolumn{2}{|l}{} \\
\end{tabular}

\section{SCHOLARONE" \\ Manuscripts}




\title{
Moderating Claims and Disputes through Collaborative Procurement
}

\begin{abstract}
Purpose: Following the global financial crisis in 2008, the construction sector in UAE has been facing emergent criticisms for growing adversarial culture and rising prevalent claims and disputes between stakeholders. The complex, large size and fast track nature of construction projects in UAE, make project management very challenging under the commonly used traditional procurement routes. This paper aspires to examine whether implementing collaborative procurement approaches can facilitate resolving the escalating number of claims and disputes in the UAE construction industry.
\end{abstract}

Design/methodology/approach: Considering the nature of the study, a quantitative method was selected to realize the research objectives. The questionnaire was uploaded using online survey facility and distributed through e-mails and professional networks. The questionnaire was piloted with experts to assess whether the questions are unambiguous, easy to respond and intelligible. The feedbacks received were mostly positive with few comments and recommendations. The pilot responses were incorporated and the questionnaire was modified before the final sending out. The questionnaire survey consisted of six main sections to fulfill the research objectives.

Findings: Around three-quarters of the experts believe that the relationship is adversarial, with lack of trust, win-lose attitude, with dismissive and opportunistic behavior. The survey reveals that the top causes of claims and disputes comprise: (a) variations due to clients initiated change requests; (b) contractors selection on low bid only rather than including quality and performance considerations; and (c) unfair risk allocation where majority of risks are transferred to contractors. 
The findings also identify eight collaborative practices which have crucial positive impact such as: (1) early identification of problems; (2) better communication; (3) enhanced trust and teamwork. Originality/value: This research contributes to the enhancement of the management of claims and disputes for construction projects, which encompasses: (a) the key characteristics of collaborative arrangements to improve the adversarial construction culture comprise: mutual respect, openness, fairness and non-opportunistic behaviours; (b) the foremost roles of collaborative procurement in reducing claims and disputes embrace: early identification and resolution of problems, enhanced trust and teamwork spirit, improved relationships and better quality communication; (c) the major practical barriers of implementing collaborative approaches incorporate: lack of awareness of their benefits, primitive legal framework of partnering arrangements, lack of transparency in procurement processes.

\section{Keywords}

UAE construction industry, collaborative procurement, traditional systems, claims, disputes, cultural change. 


\section{Introduction}

Construction industry has always been a major contributor to UAE's economy. UAE construction sector have revived itself from the economic downturn of 2008 and currently have massive projects being launched in preparation of World Expo 2020 in Dubai. According to a study conducted by Dubai Chamber of Commerce, contribution of construction sector to GDP was $10.6 \%$ before the recession of 2008. After experiencing the slow down during the global financial crisis, construction industry has regained its momentum with GDP contribution of $10.3 \%$ in year 2011. GDP contributions of the construction industry for year2020 is projected to record $11.5 \%$.

Most of the construction projects in UAE experience cost and time overruns leading to complicated disputes (Faridi and El-Sayeh, 2006). Legal disputes in Middle East are longest to settle and these delays are due to a large back log of claims existing in the industry. These delays prompt firms to bring in specialist from outside the region to get speedier solution. According to surveys conducted on global construction disputes by EC Harris (2012), disputes in terms of value and length of time is largest in the Middle East and some of the main reasons are identified as: (a) failure to suitably manage the contract; (b) inadequate design information or employer requirements; 3) changes imposed by employer; (c) failure to mutually agree on extension of time claims and compensation; 4) transferring risk from clients to contractors unrealistically.

Construction industry in UAE largely relies on traditional procurement routes. Familiarity of existing traditional approach and cost certainty at the onset of the project make clients reluctant to 
adopt other alternative collaborative approaches. But they do not realize that these traditional routes may not always offer best value for money and time certainty (Asamoah, 2012).

Therefore, the primary objective of this paper is to investigate the suitability of collaborative procurement approaches in UAE construction industry and to assess their impact and effectiveness in reducing construction claims and disputes.

\section{Collaborative arrangements}

This section highlights some of the relevant literature on collaborative procurement approaches such as partnering, alliancing, joint venture, framework contracts and other integrated approaches. Some of their benefits and challenges are also presented. Wide range of construction procurement studies indicated that the short falls in project performance is attributed to lack of inter-firm collaboration (Suprapto, et al, 2015).

Construction projects are regarded as successful when it is completed within the planned time, budget, quality constraints and achieves high level of client satisfaction. The fulfillment of these criteria has long been associated with problems in procurement methods. Procurement methods have a significant role in shaping the success of a project (Naoum and Egbu, 2015).

According to Rahman and Kumaraswamy (2005), procurement and contract arrangements should be flexible enough in order to account for future uncertainties of construction projects. Any unforeseen risk shall be dealt with as a joint risk management (JRM) strategy during construction 
stage with the joint efforts of all associated parties. Clients shall select procurement arrangements considering relational approaches and incentives; and creating a balance between "control" and "flexibility". In this pretext, many construction clients have looked into alternative ways of working with the contractors which led to the development of formal collaborative working arrangements like partnering, integrated approaches, joint ventures and alliancing. The following are some definitions of these types of collaborative arrangements.

- Partnering involves a long-term commitment between the project parties to achieve specific business objectives and to maximize effectiveness of company resources and capabilities for the success of the project. It requires replacing the conventional mindsets and traditional relationship in construction industry to a broader shared culture without organizational boundaries (Chan et. al., 2006).

- Alliancing is a way to deliver major capital assets where all the stakeholders works together in integrated and collaborative manner in good faith and for the integrity of the project. All decisions and risks are managed jointly by the parties and mutually share the outcomes of the project (Lahdenpera, 2012).

- Joint Ventures (JV) are formed for large scale engineering and complex projects. International Construction Joint Ventures (ICJV) involves a network of contractual relationships with at least two construction companies, Trust plays a key factor in defining success of JV projects (Girmscheid and Brockmann, 2010).

- Framework agreements are crafted between clients and contractors for the purpose of establishing terms governing the contract during a given time period (ISO, 2010). Through 
these agreements clients can develop collaborative procurement relationships with contractors and supply chain for long term gains (Watermeyer, 2013).

\subsection{Benefits of collaborative arrangements}

A research conducted by Buvik and Rolfsen (2015) states that previous work experience between project parties helps in building social relationship between project members which in turn has substantial effects in trust development and integration during early phases of construction projects. A study by Chan, et al (2006) on infrastructure projects showed that these types of projects achieved better performance and least claims/disputes under partnering arrangements. The research concluded the following major benefits of partnering arrangements: (1) improved relationship between the parties; (2) improved communications; (3) better productivity; and (4) reduction in disputes and litigation.

Approaches such as partnering arrangements enhance communications and team spirits between the stakeholders: clients, consultants and contractors (Baden, 1995). Partnering provides a framework to establish common objectives and goals between the team, enhancing trust, cooperation and teamwork and encourages continuous improvement (Naoum, 2003). Chan, et. al. (2004) enumerate the following as critical factors in determining the success of partnering arrangements: (1) mutual trust between the parties; (2) early implementation of partnering arrangements in the project; (3) win-win attitude among the parties; and (4) having a realistic programme and budget. 
Several case studies have been conducted to analyze the benefits of partnering. Bresnan and Marshall (2000) identified the following additional benefits of partnering: (1) reduced cost with increased productivity; (2) reduced project duration because of early contractor and supplier involvement which leads to team integration; (3) continuous improvement on quality; and (4) better client satisfaction. Partnering can help in increased prospects of future business and opportunities. According to Cox and Townsend (1998) partnering arrangements increases innovation and leads to fewer confrontations between the project stakeholders.

\subsection{Barriers of collaborative arrangements}

Several authors are of the opinion that there are many barriers and challenges in achieving these claimed desirable outcomes of collaborative arrangements. Major difficulties in implementing collaborative arrangements according to Chan et. al. (2006) are: (1) uneven levels of commitments of the parties involved; (2) commercial pressures faced by the parties which force them to compromise partnering attitude; and (3) public sector faces the most difficulties, as it is usually less flexible in nature and has stringent procedures concerning variations. Some other documented barriers in the literature consist of:

- Reluctance of clients in fully committing to partnering arrangements (Gadde and Dubois, 2010).

- Difficulties of implementing these arrangements due to institutional setting which has been historically molded on adversarial culture existing between project stakeholders (Anvuur and Kumaraswamy, 2007). 
- Lack of top management commitment and collaborative mindset (Alderman and Ivory, 2007).

- Practical problems in adapting strategic decisions regarding partnering arrangements at corporate levels into actual behavior at constructional and operational level (Bresnan and Marshall, 2000).

- Lack of favorable legal framework and political support in many countries.

- $\quad$ Lack of strong private consortium and economic stability (Dulaimi et. al., 2010).

- Absence of transparent and competitive tender and procurement process.

\subsection{Critiques of collaborative arrangements}

In contrast, there are other studies which claim that there are severe challenges in gaining the benefits from collaborative approaches such as partnering. A study by Anvuur and Kumaraswamy (2007) states that characteristics like mutual trust, accountability and cohesion do not emerge easily. These can be formed only through long and sometimes difficult interactions which ultimately establish a social relation and binds the stakeholders for a common goal.

A research by Bresnan and Marshall (2000) indicates that the success stories of collaborative approaches is mainly based on their experiences in countries such as UK, USA and Australia; therefore, organizations need to be more cautious while exercising them in other national contexts. Real benefits of these collaborative routes can be achieved only by customizing them based on local conditions. 
Collaborative routes require a cultural change in industries which has a wide range of underlying issues, problems and dilemmas. The quasi experimental evaluation carried out by Nystrom (2008) proposes that there are no tangible benefits arising out of approaches such as partnering. These contradicting opinions have still to be explored in the context of more projects procured and completed through collaborative approaches and whether the desired actual objectives and benefits have been attained.

\section{Construction claims and disputes}

\subsection{Causes of claims/disputes}

According to Arcadis report (2015) there are two main common causes of construction disputes: (a) the economic environment affecting projects; and (b) the quality of contract administration. Other issues include faster paced schedules for complex projects which feed into construction disputes. The report revealed that, during 2014, the average value of a dispute was $\$ 51$ million and the average period was 13.2 months. The report also exposed that the top ranked methods of dispute resolution were: (1) party to party negotiation; followed by (2) mediation; then (3) arbitration.

In recent years, the construction industry has escalated in terms of complexity and competitiveness and has gained reputation for risks, disputes and associated controversies. According to Ren et. al. (2001) the main reasons for the vast numbers of claims in the construction industry can be associated to the following categories of features: 
- Social Factors: There is increasing pressure from the society on the industry to be more competitive in terms of cost, timeframe, quality and sustainability. This makes the industry riskier.

- Industrial factors: The large and diverse numbers of stakeholders, extent and complexity of projects, uncertainties in the construction environment, unbalanced risk allocation, inappropriate procurement system etc. contributes to construction claims.

- Project Factors: Unrealistic project planning with unacceptable and squeezed project timeframe, unforeseeable site conditions, changes brought by Clients, incomplete design, lack of constructability and force majeure events are some of the direct causes of the claims.

Iyer et. al. (2008) investigated the key effects of claims and disputes on project and summed them as: (1) disturbs the project progress; (2) deteriorates relation between owners and contractors; (3) leads to time and cost overrun; and (4) sends bad vibes to investors in the construction industry.

Construction disputes and appropriate resolutions in public private partnerships were evaluated by Chou et. al. (2016) in Taiwan construction sector. The study used artificial neural networks and regressions techniques to classify the types of disputes and their resolutions. The key factors for classifications comprise: project type and scale; private capital investment ratio; type of PPP; industrial background of the institutions involved; concession period; and central/local government involvement. 
Chaphalkar et. al. (2015) developed multilayer perceptron neural networks to predict the outcomes of construction project disputes in India. The influencing factors utilized for these forecasting models encompass: variation orders by the owner; insufficient data at tendering stage; change in specifications due to inconsistency in documents; unforeseen conditions beyond the control of the contractor; and change in the rate of item due to change in specifications.

\subsection{The impact of procurement approach on claims/disputes}

The association between procurement, claims and dispute management in the construction industry has been studied widely by many researchers. One of the main reasons for inter organizational disputes in the industry has been testified as poor choice of procurement strategy (Rowlinson and McDermott, 1999). According to Laedre et.al, (2006) improper selection of procurement routes may lead to time and cost overruns in a project and can lower the quality too.

Research undertaken by Conlin, et.al. (1996) have concluded that conflicts due to payment, budget, quality, performance, delays and time can be associated with certain procurement systems in practice. Delays in early involvement of procurement department in a project can reduce the benefits gained from the chosen procurement routes. Project procurement system like partnering and design-build routes are now being increasingly adopted in the construction industry to reduce claims and enable better claims management. It is generally believed that procurement routes like partnering arrangements and design-build route can help to reduce conflicts and foster close collaboration between the project stakeholders (Ren, et. al. 2001). 
Unbiased agreement with a fair risk allocation is the foundation for mutual trust and respect. A fair contract with even-handed risk sharing and liabilities will encourage bidders to provide competitive bids which otherwise will be highly inflated to account for the unfair risk transfer (Pawson and Thompsun, 2013). According to Ren et al. (2001) project stakeholders especially clients must exhibit fair-minded attitude to risk allocation and during selection of contractor, contract forms and procurement systems. Equity in risk allocation by proper selection of contracts type and procurement system can lessen root causes of claims.

According to Touran et al. (2008) procurement policies of clients can be of three types: (1) low bid procurement, (2) qualification based procurement, and (3) value based procurement. Low bid procurement is the foremost reason behind most of the issues in construction procurement system. The potential benefits from competitive tendering is being over-estimated and glorified by clients in the construction industry (Gadde and Dubois, 2010).

Various contractors in traditional procurement adopt an opportunist strategy at the onset whereby they hide the mistakes and lack of buildability of the design and reduce the quality. The client is forced to alter the design during construction stage to bring in buildability and to improve on quality and design. The contractors later-on exercise their contractual rights and claim for all the additional work due to design alterations. It would be highly alarming for the client organization to know that in traditional contracts, contractor if given the right to bid for only one project, they always prefer to choose the one with highest claim potential (Laan et,al., 2011). Efficiency of procurement practices plays a leading role in the modern world to eliminate wasteful activities in 
construction. Procurement faces frequent challenges depending on the 'market structure', 'legal framework' and 'political environment' of the country (Dimitri, et. al. 2006).

\title{
3.3. UAE claims and disputes
}

Analysis by MarketLine (2016) of UAE construction industry shows that it had a value of $\$ 130.5$ billion in the year 2015, with a Compound Annual Growth Rate (CAGR) of 7.3\% between the years 2011-2015.

\begin{abstract}
Most of UAE construction industry relies on traditional methods of procurement, with a price based competitive tendering process. Though it is wrong to attribute all failures of the construction industry to the choice of procurement methods, it has undoubtedly serious limitations and disadvantages to the industry. Major drawbacks of traditional procurement routes are the weakening of stakeholder relationship caused by disputes mainly arising from contract variations. Construction management and constructability issues also arise due to the separation of design and construction teams (Naoum, 2003).
\end{abstract}

There is a rising trend of claims and disputes within the UAE construction industry. A study conducted by Zaneldin (2006) shows that the claims in UAE can be broadly classified into six different types which are due to: (1) ambiguities in contract; (2) delays, (3) acceleration; (4) project changes; (5) extra work; and (6) site conditions. The claims due to project changes and extra work are the most frequent in UAE. 
Zaneldin (2006) presented a summary of practitioners' recommendations from Dubai Municipality and Abu Dhabi Planning Department to prevent or reduce claims in UAE industry. Some of these opinions covered the following suggestions:

- Provide reasonable time for project planning and design completion.

- Contract to be drafted carefully and clearly with no ambiguities

- Develop mutual cooperation and trust between the project parties.

- Incorporate constructability into the different project stages.

- Appropriately log all work progress and job records on a timely manner.

\section{Research Methodology}

The main purpose of this research is to look into the effectiveness of collaborative procurement in controlling claims and disputes in UAE construction industry. Considering the nature of the study, a quantitative method was selected to realize the research objectives. A questionnaire survey was utilized for data collection, which can appropriately reach out for the targeted population of industry professionals. The questionnaire was uploaded using online survey facility and distributed through e-mails and professional networks. All the responses were examined to ensure reliability of the survey.

The questionnaire was piloted to assess whether the questions are unambiguous, easy to respond and intelligible. The pilot study included a senior cost professional, a project manager, academics and few other practitioners. The feedbacks received were mostly positive with few comments and 
recommendations. The pilot responses were incorporated and the questionnaire was modified before the final sending out. The questionnaire survey consisted of six main sections to fulfill the research objectives as follows:

- Section 1: general information - this section consisted of questions related to the respondent's designation and experience, other questions designed to understand the type and nature of organizations and its size as annual turnover.

- Section 2: claims and disputes in UAE construction industry - the questions under this section was formulated to understand the type, nature and causes for the claims and disputes in UAE construction industry from the perspective of the industry experts.

- Section 3: procurement routes in UAE construction industry - in this section the respondents were asked about the commonly followed procurement routes in their companies, their views on its suitability for the industry.

- Section 4: collaborative approaches - in this section one of the question was devised to evaluate respondent's basic understanding about collaborative approaches as there are many misconceptions in the industry. Others were aimed at understanding the opinion of the respondent's about the characteristics and suitability of collaborative procurement to reduce claims and disputes in UAE industry.

- Section 5: barriers in implementing collaborative approaches in UAE - these questions were directed to understand the views of respondents as to why the collaborative approaches are not so common in UAE and the respondents' willingness to work in a collaborative environment in future. 


\section{Analysis and discussions}

\section{Type of organisations participated in the survey}

The targeted population of the survey included professionals from various organisations such as clients, consultants, main contractors and subcontractors mainly operating in UAE. A total of 61 completed responses were obtained out of 150 questionnaires distributed, with a response rate of $41 \%$. Figure (1) presents the professional background of the respondents.

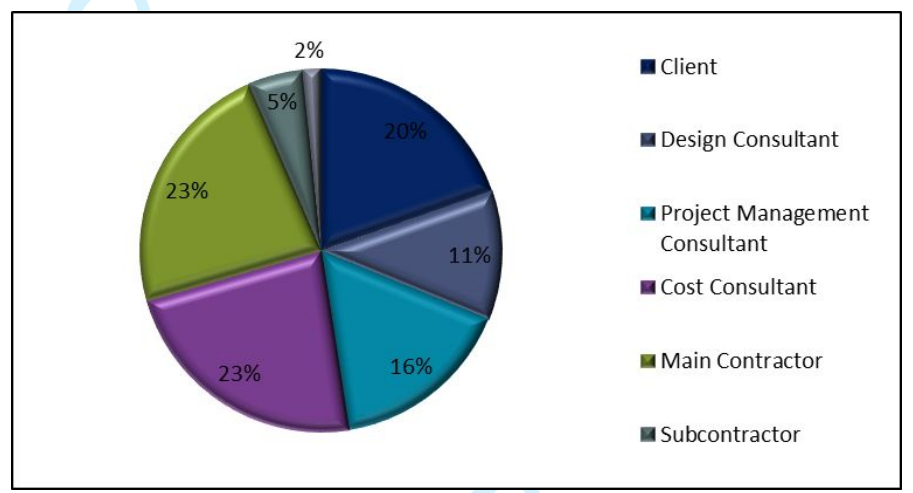

Figure (1): Type of organisations and professional background

\section{Type of construction sectors and projects}

Figure (2) depicts the experts from different sectors responded to the questionnaire. Around $72 \%$ of the respondents were associated with the building sector followed by $61 \%$ for infrastructure sector. Considering the market profile of the UAE construction industry this is a common scenario, as the country's major projects are in building and infrastructure sectors. The other sectors like MEP, marine and petrochemicals have a good response rate too. This survey will have a balanced reflection of the UAE construction industry. 


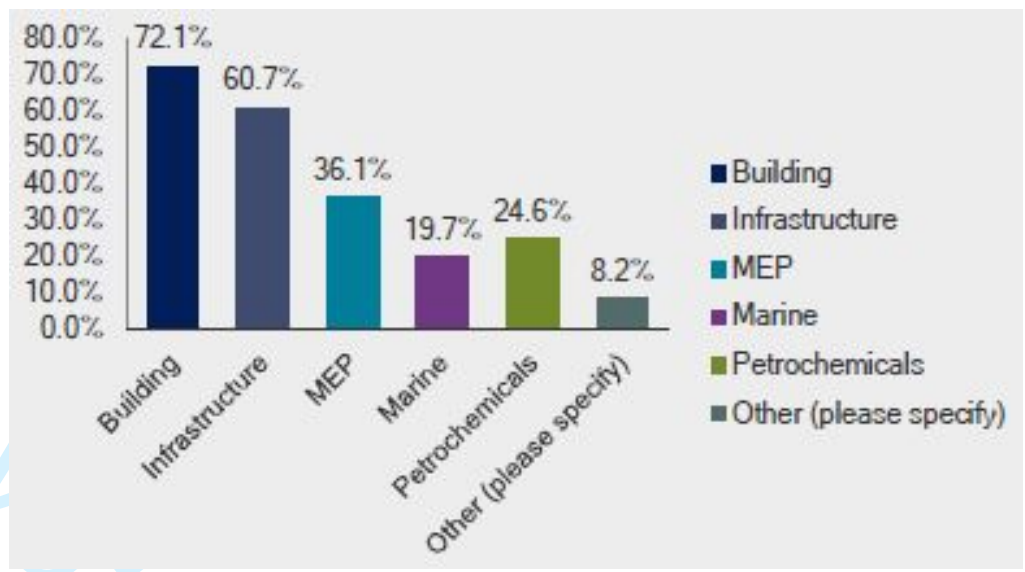

Figure (2): Types of construction sectors

\section{Respondents' experiences with collaborative methods in construction}

Figure (3) shows that about $31 \%$ of the respondents did not have any prior experience with collaborative procurement approaches, which is in line with studies conducted in the UAE that the collaborative procurement routes are not widely used in UAE industry (Dalley and Barton, 2016). The rest $69 \%$ of the respondents have a fair experience with collaborative approaches, and around $23 \%$ have more than 5 years experience with collaborative approaches.

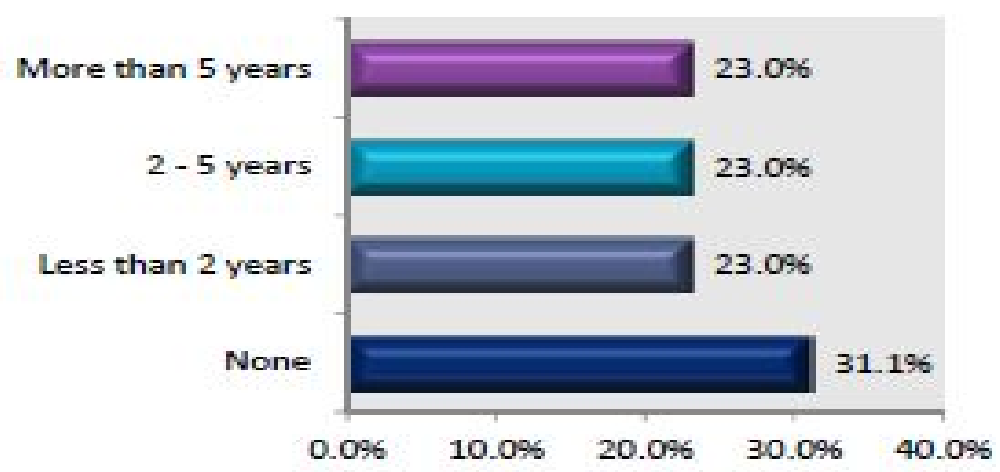

Figure (3): Respondents' experiences in collaborative approaches 


\section{Relationships between project stakeholders}

Figure (4) depicts the opinions of the experts about the relationships between construction project stakeholders. About only quarter of the respondents think that relationship is friendly or gain/pain share type of approach. On the other hand, around $77 \%$ of the experts believe that the relationship is either adversarial, lack of trust, win-lose attitude, or dismissive and opportunistic behavior.

These responses are an indication of a strained relationship prevalent among the project parties as suggested in the literature review (Spencer, 2013). The increasing number of disputes in the region, according to surveys conducted by EC Harris (2012) is a reflection of these strained relations between construction projects' stakeholders.

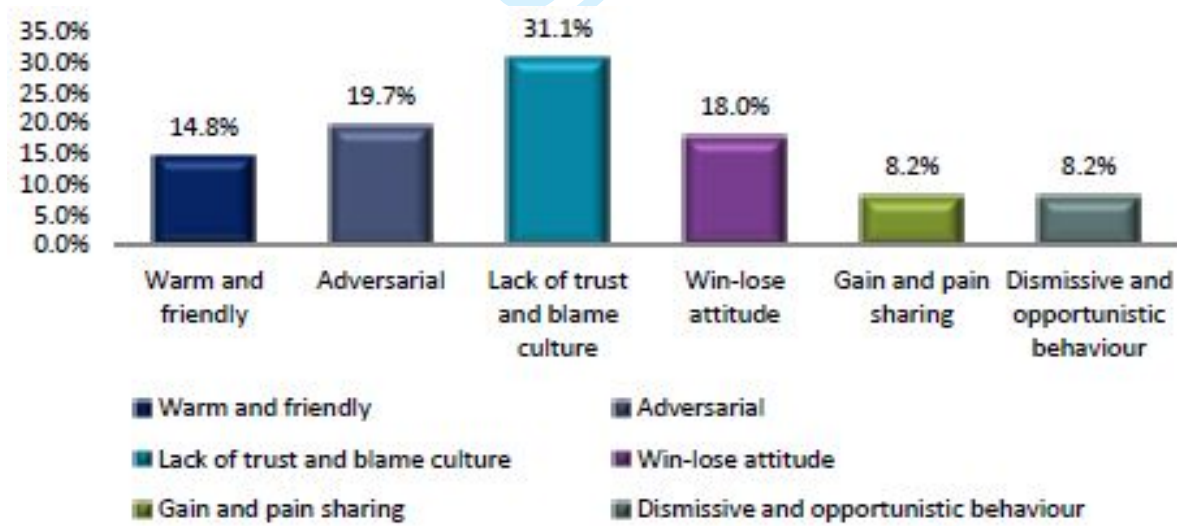

Figure (4): Relationships between project stakeholders 


\section{Causes of claims and disputes in the UAE construction industry}

The experts were asked to rate the different causes for claims and disputes prevalent in the industry on a scale of 1 (least significant) to 5 (most significant). Table (1) presents the results of ranking these factors, which shows that the top causes are: (a) clients change requests; (b) contractors selection on low bid only rather than including quality and performance considerations; (c) unfair risk allocation on contractors; (d) unrealistic project planning and timeframe. On the contrary, the least influential causes are: (a) shortage of manpower; (b) shortage of material; (c) force majeure events. Some of these findings are in line with the study conducted by Zaneldin, (2006) on construction claims.

Table (1): Causes of construction claims and disputes

\begin{tabular}{|c|c|c|c|c|c|c|c|}
\hline \multirow{2}{*}{ Causes for Claims and Disputes in UAE Construction Industry } & \multicolumn{5}{|c|}{ Response Ratings ( 1 -least to 5 -highest) } & \multicolumn{2}{|c|}{ Overall } \\
\hline & 1 & 2 & 3 & 4 & 5 & Index - RII & Rank \\
\hline $\begin{array}{l}\text { Variations due to client initiated changes during construction } \\
\text { stages }\end{array}$ & 3 & 6 & 10 & 22 & 20 & $76.39 \%$ & 1 \\
\hline $\begin{array}{l}\text { Selection of contractors by low bid procurement rather than } \\
\text { quality and value based procurement }\end{array}$ & 2 & 10 & 17 & 18 & 14 & $70.49 \%$ & 2 \\
\hline $\begin{array}{l}\text { Unfair risk allocation where majority risk is transferred to the } \\
\text { contractor }\end{array}$ & 2 & 6 & 23 & 19 & 11 & $70.16 \%$ & 3 \\
\hline $\begin{array}{l}\text { Fast track nature of the projects with unrealistic project planning } \\
\text { and project timeframe }\end{array}$ & 7 & 8 & 14 & 15 & 17 & $68.85 \%$ & 4 \\
\hline Nonflexible attitude and disagreement over scope variations & 8 & 13 & 17 & 14 & 9 & $60.98 \%$ & 5 \\
\hline $\begin{array}{l}\text { Poor co-operation and communication between the parties due to } \\
\text { the fragmentation of construction process }\end{array}$ & 4 & 15 & 19 & 21 & 2 & $60.66 \%$ & 6 \\
\hline Poor performance from the contractor & 4 & 17 & 17 & 20 & 3 & $60.33 \%$ & 7 \\
\hline $\begin{array}{l}\text { Constructability issues due to separate design and construction } \\
\text { phases }\end{array}$ & 7 & 12 & 20 & 18 & 4 & $60.00 \%$ & 8 \\
\hline Lack of mutual trust and openness between the parties & 7 & 15 & 26 & 8 & 5 & $56.39 \%$ & 9 \\
\hline Authority rules and regulations & 6 & 20 & 21 & 11 & 3 & $55.08 \%$ & 10 \\
\hline Shortage in availability of manpower & 10 & 25 & 14 & 9 & 3 & $50.16 \%$ & 11 \\
\hline Shortage in availability of material & 15 & 22 & 16 & 5 & 3 & $46.56 \%$ & 12 \\
\hline Force majeure events & 22 & 23 & 7 & 4 & 5 & $42.62 \%$ & 13 \\
\hline
\end{tabular}




\section{The basis of contractors' selection: lowest bid vs. performance, quality and value}

A significant $82 \%$ of the respondents are of the opinion that Clients in UAE 'mostly' consider lowest bidding criteria in selecting contractors rather than a performance, quality and value based selection. A further 7\% respondents have stressed that the clients do that 'always', Figure (5).

In the previous question, Respondents have identified the 'selection of contractors on the basis of lowest bids' as the second major reason for disputes in construction. In order to become competitive, contractors are forced to become opportunistic whereby they don't declare the mistakes and lack of buildability in the design. Laan et.al. (2011) revealed that contractors lower their bid as they foresee lot of claim potential during construction stages, which leads to time and cost overruns in the project. Disputes on quality and performance of the works are also common in the post contract stages.

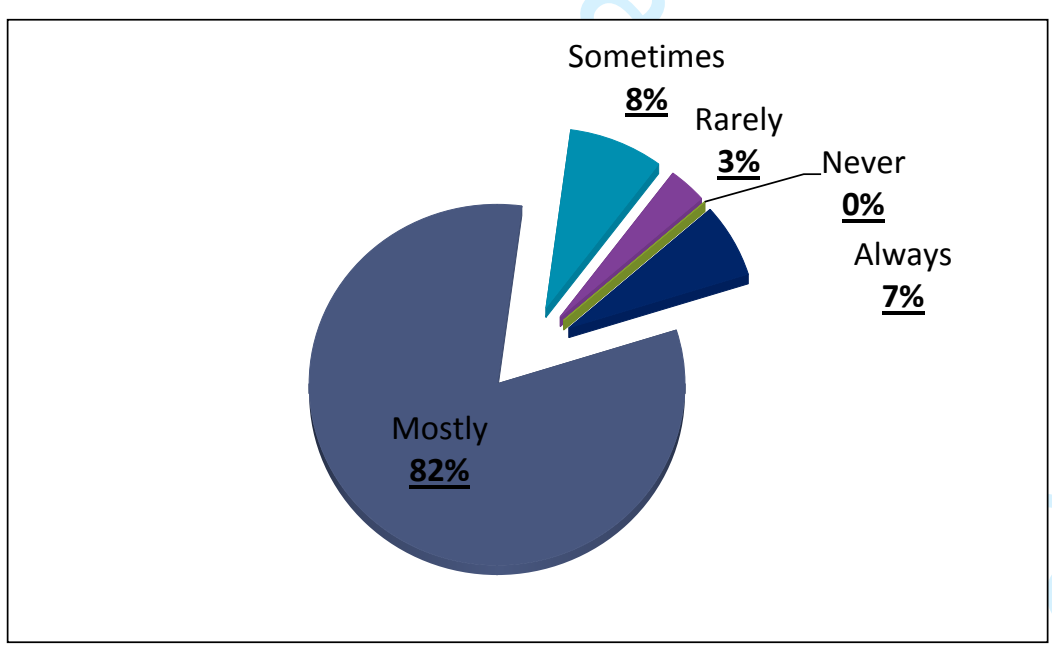

Figure (5): The basis of contractors' selection 


\section{The impact of incentivized payment mechanism on lowering construction disputes}

Slight majority of the respondents are not strongly supporting the statement. $56 \%$ of them selected 'sometimes' or 'rarely' and 44\% of them have chosen the options 'always' or 'mostly', Figure (6). According to literature studies incentives can motivate the parties and increase efficiency, thereby, reducing disputes (Wamuziri, 2013). However, the views of the experts in the UAE suggest that disputes in the industry are more deeply rooted which cannot be fixed by incentivized payment mechanisms alone.

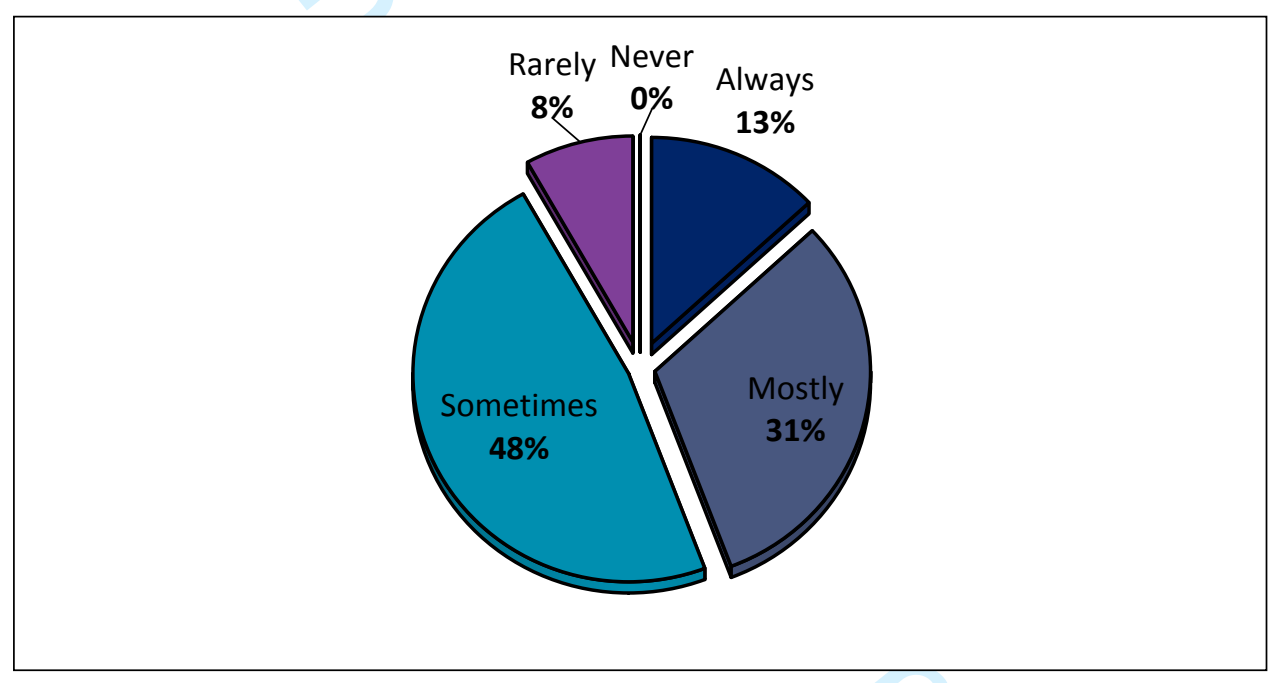

Figure (6): Incentivized payment mechanism

\section{The influence of early contractor involvement (ECI) on reducing claims and disputes}

Around two third respondents believe ECI can benefit the project and lower claims and disputes, Figure (7). This is in support of the study undertaken by Larea and Watermeyer (2013), where early contractor involvement is considered beneficial for constructability aspects and thereby minimizing issues arising at later stages. 


\section{The impact of current procurement practices on raising construction claims}

According to Rowlinson and McDermott (1999), disputes in construction industry are linked with poor choice of procurement strategies. This has been further supported by the responses received in this study where more than two third of respondents are of the opinion that current procurement practices, which is mainly traditional route, play a significant role in the increasing number of claims and disputes in UAE, Figure (8). This justifies the objective of this research to investigate the effectiveness of collaborative approaches in controlling claims and disputes, due to the limitations of current procurement practices followed in UAE.

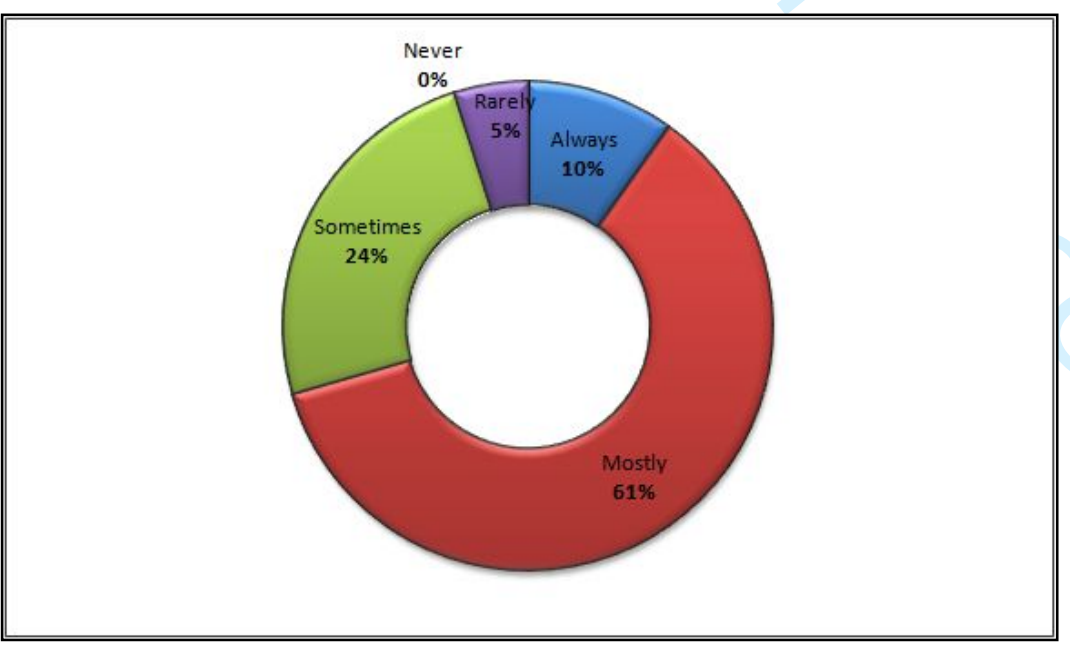

Figure (8): Impact of current procurement practices on raising claims 


\section{The influence of the characteristics of collaborative arrangements on improving the} current adversarial culture prevalent in the UAE construction industry

Figure (9) depicts some of the main characteristics which form the basis of collaborative approaches based upon relevant literature review. The questionnaire participants were asked whether they agree or not that these factors would help to improve the adversarial culture prevalent in the UAE construction industry. As shown in the results in Figure (9), between 77\% and 87\% of the respondents agreed or strongly agreed that each of the five factors will have positive impact on the industry.

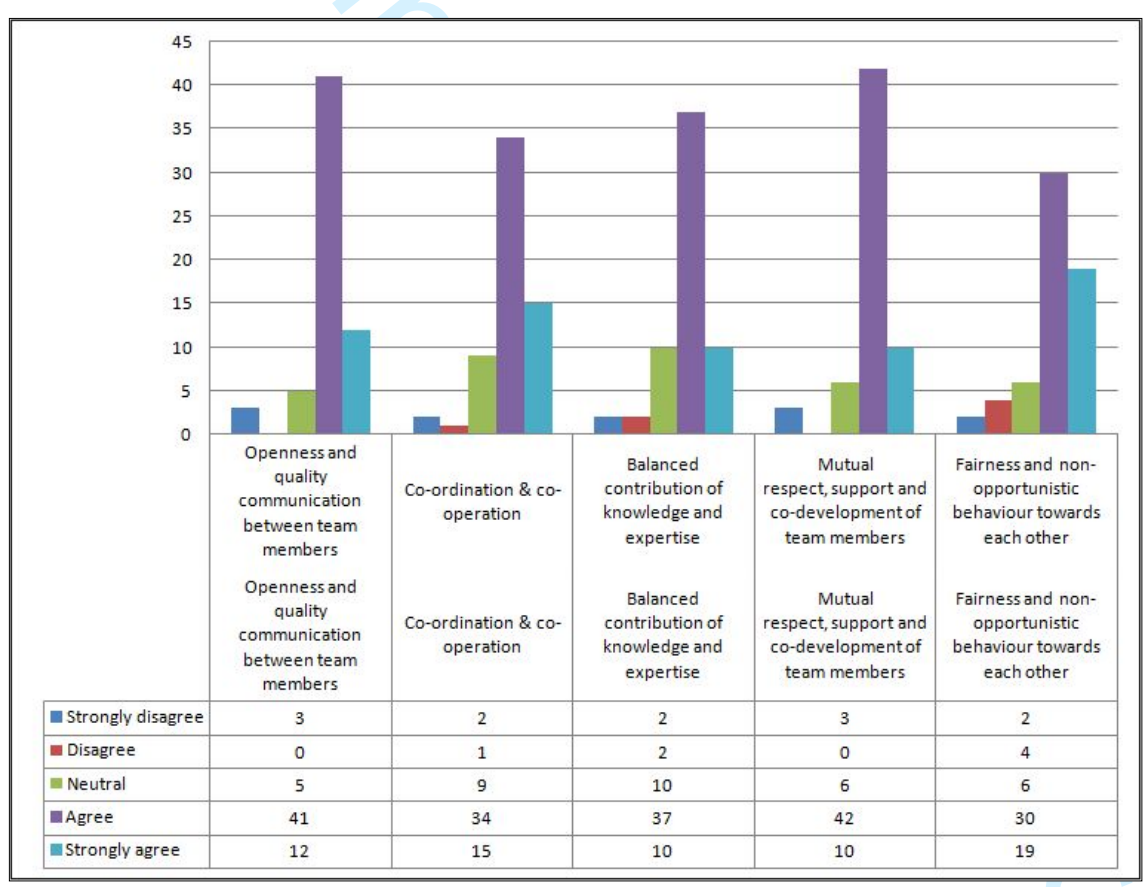

Figure (9): Characteristics of collaborative approaches 


\section{The respondents' views on statements about the role of collaborative procurement in reducing claims and disputes}

Table (2) presents the impact of collaborative procurement practices on controlling and reducing claims and disputes in UAE construction industry. The questionnaire participants were requested to rate the influence of these collaborative practices. The findings confirm that all of the practices scored very high indices. Although the least influential factor was the "open book tendering and costing" but still it scored a high index of about $69 \%$, Table (2).

Table (2): Ranking of collaborative procurement practices

\begin{tabular}{|c|c|c|c|c|c|c|c|}
\hline \multirow{2}{*}{$\begin{array}{c}\text { Role of collaborative procurement in re ducing claims and } \\
\text { disputes. }\end{array}$} & \multicolumn{5}{|c|}{$\begin{array}{c}\text { Response Ratings ( 1-Strongly Disgree to } 5 \text { - } \\
\text { Strongly Agree) }\end{array}$} & \multicolumn{2}{|c|}{ Overall } \\
\hline & 1 & 2 & 3 & 4 & 5 & Index - RII & Rank \\
\hline Early identification and resolution of problems & 1 & 2 & 2 & 41 & 15 & $81.97 \%$ & 1 \\
\hline $\begin{array}{l}\text { Enhanced trust and teamwork and long term relationship between } \\
\text { the parties }\end{array}$ & 2 & 0 & 3 & 43 & 13 & $81.31 \%$ & 2 \\
\hline $\begin{array}{l}\text { Improved relationship between the parties and better } \\
\text { communication }\end{array}$ & 1 & 0 & 5 & 46 & 9 & $80.33 \%$ & 3 \\
\hline Appropriate risk allocation and joint risk resolution & 1 & 1 & 8 & 42 & 9 & $78.69 \%$ & 4 \\
\hline $\begin{array}{l}\text { Increased productivity and quality with continuous improvement } \\
\text { and innovation }\end{array}$ & 1 & 2 & 7 & 42 & 9 & $78.36 \%$ & 5 \\
\hline Better control on cost and time & 1 & 2 & 11 & 35 & 12 & $78.03 \%$ & 6 \\
\hline Incentivised payment mechanism which is commonly adopted & 1 & 2 & 21 & 28 & 9 & $73.77 \%$ & 7 \\
\hline Open book tendering and costing & 1 & 5 & 27 & 22 & 6 & $68.85 \%$ & 8 \\
\hline
\end{tabular}

\section{Practical difficulties/barriers in implementing collaborative arrangements in $U A E$ construction industry}

Despite the various advantages of collaborative approaches, it is not so popular in UAE construction industry. Respondents were asked about their views on the barriers which they foresee in the implementation of collaborative procurement routes in UAE. The foremost barrier identified 
is the lack of awareness among clients on the benefits of collaborative procurement routes. Respondents were also of the opinion that legal frameworks for collaborative approaches are at primitive stages. Market structure of UAE is recognized as another reason, Table (3). On the contrary respondents gave lower priority to political environment of the country as they do not seem to support this statement. Respondents also felt prevalent adversarial culture is of lower significance compared to other impediments.

\section{Table (3): Practical difficulties/barriers in implementing collaborative routes}

\begin{tabular}{|c|c|c|c|c|c|c|c|}
\hline \multirow{2}{*}{$\begin{array}{l}\text { Practical difficulties in implementing collaborative } \\
\text { arrangements in UAE. }\end{array}$} & \multicolumn{5}{|c|}{$\begin{array}{c}\text { Response Ratings ( 1-Strongly Disgree to } 5 \text { - } \\
\text { Strongly Agree) }\end{array}$} & \multicolumn{2}{|c|}{ Overall } \\
\hline & 1 & 2 & 3 & 4 & 5 & Index - RII & Rank \\
\hline $\begin{array}{l}\text { Lack of awareness among the client on the benefit of collaborative } \\
\text { approaches }\end{array}$ & 0 & 6 & 10 & 32 & 13 & $77.05 \%$ & 1 \\
\hline Legal framework for partnering approaches are at primitive stages & 0 & 2 & 13 & 39 & 7 & $76.72 \%$ & 2 \\
\hline Market structure of UAE & 1 & 3 & 11 & 40 & 6 & $75.41 \%$ & 3 \\
\hline $\begin{array}{l}\text { Absence of transparent and competitive tender and procurement } \\
\text { process }\end{array}$ & 1 & 6 & 13 & 32 & 9 & $73.77 \%$ & 4 \\
\hline $\begin{array}{l}\text { Clients believe partnering requires more effort and brings up-front } \\
\text { cost to the project }\end{array}$ & 0 & 7 & 14 & 33 & 7 & $73.11 \%$ & 5 \\
\hline Prevalent adversarial culture in the industry & 1 & 4 & 25 & 23 & 8 & $70.82 \%$ & 6 \\
\hline Political environment of the Country & 1 & 11 & 27 & 19 & 3 & $63.93 \%$ & 7 \\
\hline
\end{tabular}

\section{Conclusion}

In this paper the characteristics of collaborative procurement routes and its effectiveness in controlling disputes were examined. The opinions and feedbacks from the survey were mostly in accordance with literature review conducted. The respondents were optimistic about the benefits of collaborative approaches and believe it can help to resolve the adversarial culture prevalent in UAE industry and reduce disputes. 
The study showed that effective social relationship, non-opportunistic behavior, mutual respect and trust among the project parties are significant in maintaining a healthy work atmosphere and lead to fewer disputes in construction projects. The need of prioritizing project objectives over individual objectives were widely supported by the respondents. The survey responses were positive and welcoming the approaches for collaboration in construction projects. Relationships between the project parties were analyzed through the survey and it was eminent that lack of trust and blame culture was prevalent in the industry.

The literature review reveals that organizations need to be more cautious while exercising collaborative approaches in different contexts at different countries. Real benefits of these collaborative routes can be achieved only by customizing them based on local conditions. Collaborative routes require a cultural change in the local industries in different countries which has a wide range of underlying issues, problems and challenges.

The main findings of this study concluded that: (a) the key characteristics of collaborative arrangements to improve the adversarial construction culture comprise: mutual respect, openness, fairness and non-opportunistic behaviours; (b) the foremost roles of collaborative procurement in reducing claims and disputes embrace: early identification and resolution of problems, enhanced trust and teamwork spirit, improved relationships and better quality communication; (c) the major practical barriers of implementing collaborative approaches incorporate: lack of awareness of their benefits, primitive legal framework of partnering arrangements, lack of transparency in tendering and procurement processes. 


\section{References}

Alderman, N. and Ivory, C. (2007) Partnering in major contracts: Paradox and metaphor. International Journal of Project Management, 25(4), 386-393.

Anvuur, A.M. and Kumaraswamy, M.M. (2007) “Conceptual model of partnering and alliancing”. ASCE Journal of Construction Engineering and Management, 133(3), 225-234.

Arcadis, (2015) Global construction disputes report: the higher the stakes the bigger the risk, Arcadis group.

Asamoah, W. (2012) "Transforming Middle East Procurement". Available online at http://www.fgould.com/middle-east/articles/transforming-middle-east-procurement. Accessed on 12 March 2016.

Baden, H.R. (1995) Project Partnering Principle and Practice. London: Thomas Telford.

Bresnen, M and Marshall, N. (2000) "Partnering in construction: a critical review of issues, problems and dilemmas". Construction Management and Economics, 18, 229-237.

Buvik, M.P. and Rolfsen, M. (2015) "Prior ties and trust development in project teams - A case study from the construction industry". International Journal of Project Management, 33, 14841494. 
Chan, A., Chan, D., Chiang, Y., Tang, B., Chan, E. and Ho, K. (2004) "Exploring critical success factors for partnering in construction projects". Journal of Construction Engineering and Management, 130(2), 188-198.

Chan, A., Chan, D., Fan, L., Lam, P. and Yeung, J. (2006) "Partnering for construction excellence: A reality or myth?", Building and Environment 41, 1924-1933.

Chaphalkar N.B., Iyer K.C. and Patil S.K. (2015) "Prediction of Outcome of Construction Dispute Claims Using Multilayer Perceptron Neural Network Model”, International Journal of Project Management, 33, 1827-1835.

Chou J.H., Hsu S.C., Lin C.W. and Chang Y.H. (2016) "Classifying Influential Information to Discover Rule Sets for Project Disputes and Possible Resolutions", International Journal of Project Management, 34, 1706-1716.

Conlin, J.T., Langford, D.A. and Kennedy, P. (1996) The relationship between construction procurement strategies and construction contract disputes, "north meets south". CIBW92, Department of Property Development and Construction Economics, University of Natal. 66-82.

Cox, A. and Townsend, M. (1998) Strategic Procurement in Construction: Towards better practice in the management of construction supply chains. Thomas Telford. 
Dalley, I. and Barton, N. (2016) Briefing: Public-private partnerships in the GCC: a changing landscape. Management, Procurement and Law, Proceeding of ICE, 1-3.

Dimitri, N., Piga, D. and Spagnolo, G. (2006) Handbook of Procurement. Cambridge University Press.

Dulaimi, M.F., Alhashemi, M., Ling, F.Y.Y. and Kumaraswamy, M. (2010) The execution of public-private partnership projects in the UAE. Construction Management and Economics, 28, $393-402$.

EC Harris, (2012) Global construction disputes: moving in the right direction. Arcadis group.

Faridi, A.S. and El-Sayegh, S.M. (2006) "Significant factors causing delay in the UAE construction industry". Construction Management and Economics, 24, 1167-1176.

Gadde, L. and Dubois, A. (2010) Partnering in the construction industry: Problems and Opportunities. Journal of Purchasing and Supply Management, 16, 254-263.

Girmscheid, G. and Brockmann, C. (2010) Inter-and Intraorganizational Trust in International Construction Joint Ventures. Journal of construction engineering and management ASCE, 136, $353-360$. 
Iyer, K.C., Chaphalkar, N.B. and Joshi, G.A. (2008) "Understanding time delay disputes in construction contracts". International Journal of Project Management 26, 174-184.

Laan, A., Noorderhaven, N., Voordijk, H. and Dewulf, G. (2011) Building trust in construction partnering projects: An exploratory case study. Journal of Purchasing \& Supply Management 17, 98-108.

Laedre, O., Austeng, K., Haugen, T. and Klakegg, O. (2006) Procurement Routes in Public Building and Construction Projects. ASCE Journal of Construction Engineering and Management, DOI: 10.1061/ASCE, 689-696.

Lahdenpera, P. (2012) "Making sense of the multi-party contractual arrangements of project partnering, project alliancing and integrated project delivery". Construction Management and Economics, 30, 57-79.

Laryea, S. and Watermeyer, R. (2014) “Innovative construction procurement at Wits University”. Proceedings of the Institution of Civil Engineers (ICE) 167, 220-231.

MarketLine (2016) http://marketline.com/ [Accessed on 28 April 2016].

Naoum, S. (2003) “An overview into the concept of partnering”. International Journal of Project Management, Vol. 21 No. 1, pp. 71-76. 
Naoum, S,G. and Egbu, C. (2015) Modern selection criteria for procurement methods in construction. International Journal of Managing Projects in Business 9, 309-336.

Nystrom, J. (2008) “A quasi-experimental evaluation of partnering”. Construction Management and Economics, 26, 531-541.

\author{
Pawson, O. and Thompsum, M. (2013) A "Perfect" Project: Engineers and the Law. Canadian \\ Consulting Engineers, 30-31.
}

\begin{abstract}
Rahman, M. and Kumaraswamy, M. (2005) "Relational Selection for Collaborative Working Arrangements". ASCE Journal of Construction Engineering and Management, 131, 1087-1098.
\end{abstract}

Ren, Z., Anumba, C.J. and Ugwu, O.O. (2001) "Construction claims management: towards an agent-based approach". Engineering, Construction and Architectural Management 8, 185-197.

Rowlinson, S. and McDermott, P. (1999) Procurement Systems: A guide to best Practice in Construction. E \& FN Spon.

Spencer, M. (2013) Practical experience in the international application of NEC. Available online at: $\underline{w w w . e c h a r r i s . c o m / c o n t r a c t s o l u t i o n s ~[A c c e s s e d ~ o n ~} 20$ May 2016]. 
Suprapto, M., Bakker, H.L. and Mooi, H.G. (2015) "Relational factors in owner-contractor collaboration: the mediating role of team working". International Journal of Project Management, $33,1347-1363$.

Touran, A., Gransberg, D.D., Molenaar, K.R., Ghavamifar, K., Mason, D.J. and Fithian, L.A. (2008) Evaluation of project delivery methods. Transportation Research Board, Washington DC.

Wamuziri, S. (2013) Payment options in collaborative procurement of major construction projects. Proceedings of the Institution of Civil Engineers, 166, 12-20.

Watermeyer R. (2013) Unpacking framework agreements for the delivery and maintenance of infrastructure. Civil Engineering, 21-26.

Zaneldin, E.K. (2006) Construction claims in United Arab Emirates: types, causes and frequency. International Journal of Project Management 24, 453-459. 